Copyright by the American Society of Agricultural and Biological Engineers. Veith, T. L.; Wolfe, M. L.; Heatwole, C. D., "Cost-effective BMP placement: Optimization versus targeting," Transactions of the ASAE. Vol. 47(5): 1585-1594 . (doi: 10.13031/2013.17636) @2004

\title{
Cost-EFFective BMP Placement: OPTIMIZATION VERSUS TARGETING
}

\author{
T. L. Veith, M. L. Wolfe, C. D. Heatwole
}

\begin{abstract}
Cost-effectiveness of nonpoint-source pollution reduction programs in an agricultural watershed depends on the selection and placement of control measures within the watershed. Locations for best management practices (BMPs) are commonly identified through targeting strategies that define locations for BMP implementation based on specific criteria uniformly applied across the watershed. The goal of this research was to determine if cost-effectiveness of BMP scenarios could be improved through optimization rather than targeting. The optimization procedure uses a genetic algorithm (GA) to search for the combination of site-specific practices that meets pollution reduction requirements, and then continues searching for the BMP combination that minimizes cost. Population size, replacement level, crossover, and mutation parameters for the GA were varied to determine the most efficient combination of values. A baseline scenario, a targeting strategy, and three optimization plans were applied to a 1014 ha agricultural watershed in Virginia. All three optimization plans identified BMP placement scenarios having lower cost than the targeting strategy solution for equivalent sediment reduction. The targeting strategy reduced average annual sediment loss compared to the baseline at a cost of $\$ 42 \mathrm{per} \mathrm{kg}$ sediment reduction/ha. The optimization plan with the same BMP choices achieved the same sediment reduction at a cost of $\$ 36 \mathrm{per} \mathrm{kg} / \mathrm{ha}$. Allocation of BMPs varied among optimization solutions, a possibility not available to the targeting strategy. In particular, the optimization solutions placed BMPs on several stream-edge fields that did not receive BMPs in the targeting strategy.
\end{abstract}

Keywords. Genetic algorithm, Geographic information system, Nonpoint-source pollution, Sediment delivery, Spatial optimization, Spatial placement, Watershed management.

$\mathrm{R}$ educing agricultural nonpoint-source (NPS) pollution through implementation of best management practices (BMPs) has received growing emphasis due to government regulations such as the Clean Water Act. As effective measures for controlling NPS pollution are identified, there is a tendency to want to control NPS pollution to the greatest extent possible by fully establishing those measures across the landscape. However, land use, soils, and topography cause some locations to be more critical than others as source areas of NPS pollution. Interaction of BMPs can further impact the amount and types of NPS pollutants transported to the watershed outlet. Because of site-specific effectiveness of BMPs, costs of NPS reduction can be reduced by selectively choosing and placing BMPs. To enable cost-effective selection and placement of BMPs, alternative BMP scenarios must be compared with respect to cost and NPS pollution control.

Field studies are limited in their practicality for comparing alternative BMP scenarios. Establishing BMPs and deter-

Article was submitted for review in March 2004; approved for publication by the Soil \& Water Division of ASAE in August 2004.

The authors are Tamie L. Veith, ASAE Member Engineer, Agricultural Engineer, USDA-ARS Pasture Systems and Watershed Management Research Unit, University Park, Pennsylvania; Mary Leigh Wolfe, ASAE Member Engineer, Associate Professor, and Conrad D. Heatwole, ASAE Member Engineer, Associate Professor, Department of Biological Systems Engineering Department, Virginia Tech, Blacksburg, Virginia. Corresponding author: Tamie Veith, USDA-ARS Pasture Systems and Watershed Management Research Unit, 3702 Curtin Road, University Park, PA 16802-3702; phone: 814-863-0888; fax: 814-863-0935; e-mail: tamie.veith@ars.usda.gov mining their long-term effectiveness takes several years, at a minimum, and results are specific to characteristics of that site and BMP application. Also, site-specific characteristics and temporal variability do not lend themselves to paired or replicate studies in which watershed response to alternate BMPs can be evaluated across otherwise similar conditions. As a result, comparative evaluation of NPS control through selective BMP application is more feasibly accomplished through plan- or performance-based methods.

Plan-based methods draw from past field studies and scientific theory to assign expected levels of control to BMPs. The ability of a plan-based method to distinguish the impact of a specific BMP/site combination is limited by the current level of understanding of the impact of that combination. Performance-based methods use simulation models to assess changes in watershed response due to alternative BMP applications. Simulation modeling can incorporate scientific knowledge to quantify general as well as site- and BMP-specific changes in response.

Targeting is a plan-based method that focuses pollution control towards critical areas that are anticipated to contribute most heavily to NPS pollution. Criteria are specified a priori based on current understanding of BMP effectiveness in a given situation. Targeting is often based on physical characteristics or cropping practices, focusing on variables/ factors such as slope, soil type, proximity to stream, crop, and tillage practices.

Past studies describe a variety of targeting strategies. Heatwole et al. (1987) placed BMPs based on both physical and management characteristics, including hydrologic soil group, proximity to stream, and cattle density. A targeting strategy by Dickinson et al. (1990) selected areas exceeding 
a given soil loss tolerance level. Willis et al. (1994) used baseline phosphorus (P) levels, hydraulic and water budget models, and various field experiments to determine $\mathrm{P}$ load reduction effectiveness of several categories of BMPs. They also calculated BMP implementation and maintenance costs. Cost and load reduction factors were combined for each BMP to estimate individual cost-effectiveness values. Then BMPs were combined by successively adding BMPs in the order of predetermined cost-effectiveness until the desired level of $\mathrm{P}$ load reduction was achieved.

As implications of targeting criteria become better known, criteria can be made increasingly selective or variable (e.g., as a function of distance to stream). However, targeting still involves rules applied consistently across the watershed and site-independent estimates of BMP effectiveness. As such, targeting is independent of local spatial characteristics that may require more or less control. Also, spatial interactions among BMPs, which may affect both cost and pollution reduction, are not typically considered in establishing a targeting strategy. As a result, the single BMP scenario developed for the watershed based on a set of targeting criteria may or may not be the most cost-effective scenario.

In contrast to targeting, optimization is a performancebased method. Optimization procedures enable consideration of spatial variation across multiple variables and, through evaluation of numerous scenarios, incorporate the impacts of BMP interaction and site-dependent characteristics in the assessment of scenario effectiveness. Thus, an optimization procedure provides a way of meeting the same water quality goals as intended to be met by the targeting strategy, but may do so in a more cost-effective way. Use of the genetic algorithm (GA), a large number optimization heuristic, in combination with an NPS prediction model and an economic model has been found to improve BMP scenario cost-effectiveness in agricultural watersheds as compared to non-selective approaches (Srivastava et al., 2002; Veith, 2002; Veith et al., 2003).

Implementation of a targeting strategy requires only data regarding whether or not each field completely meets a set of targeting criteria. Interpretation and application of the single resulting solution are simple as compared to an optimization procedure. An optimization procedure minimally requires the same data. However, information on the extent to which each field meets individual criteria may allow more selective assignment of BMPs to each field. Detailed economic data are also needed. Additionally, an optimization procedure requires technical skill in formatting the data for a given watershed and interpreting the results to effectively understand the alternative solutions provided.

There is a trade-off between the potential benefits of achieving more selective BMP placement through optimization and the decreased data and skill requirements of targeting. The objectives of this study were: (1) to determine if selection of BMPs through optimization, a performancebased method, can identify more cost-effective BMP scenarios than targeting, a plan-based method; and (2) to determine if the cost-benefit ratio of optimization is lower than that of targeting in meeting NPS reduction goals.

\section{Case Study Watershed}

The comparison of optimization and targeting was conducted for a 1014 ha watershed in Rockingham County, Virginia (Veith, 2002). Land use in the watershed is comprised of agricultural production (77\%), forest/orchard (19\%), and farmstead/residential (4\%). Agricultural production in the watershed includes eleven dairy farms and seven beef farms. Three of the cattle farms include poultry production as well. The two major soil classifications in the watershed are Frederick silt loam (55\%) and Laidig very channery loam (16\%). These are deep, well drained soils with moderate permeability and available water capacity. Additionally, $11 \%$ of watershed has rocky outcrop. The main channel in the watershed has a flow length of about $6,000 \mathrm{~m}$ and is ephemeral, joining a perennial stream at the watershed's outlet.

\section{MeTHODS}

A baseline scenario, one targeting strategy, and three optimization plans were applied to the watershed (table 1). The baseline scenario was representative of the watershed without erosion control practices. The targeting strategy implemented a combination of basic erosion control BMPs involving changes in crop management (reduced tillage and cover cropping) and in-field operation orientation (contour and up/down slope), based on slope steepness. The three optimization plans applied the full combination of BMPs used by the targeting strategy as well as individual BMPs

Table 1. Description of evaluation runs compared in this study.

\begin{tabular}{lr}
\hline Baseline Scenario & $\begin{array}{c}\text { All cropland was managed as conventionally tilled corn silage. } \\
\text { Targeting Strategy }\end{array}$ \\
$\begin{aligned} \text { All cropland with the majority of the field slope: } \\
\text { Less than or equal to } 3 \% \text { was managed as in the baseline, and } \\
\text { Greater than 3\% was converted to minimum-tillage corn silage on the contour with a winter wheat cover crop. }\end{aligned}$ \\
$\begin{array}{l}\text { Two management variations of corn silage were available for all cropland: } \\
\text { Conventional tillage, or } \\
\text { Minimum-tillage on the contour with a winter wheat cover crop. }\end{array}$ \\
$\begin{array}{r}\text { Nine management variations were considered for any cropland field: } \\
\text { All combinations (eight total) of: } \\
\text { conventional or minimum tillage, } \\
\text { with or without winter wheat cover crop, } \\
\text { and with or without contour farming; or }\end{array}$ \\
Conversion of the row crop to forage (pasture or grass hay). \\
\hline $\begin{array}{l}\text { This plan was the same as optimization plan 2, except that hay and pasture lands were additionally available for conver- } \\
\text { sion to corn silage with or without BMPs. }\end{array}$ \\
\hline
\end{tabular}




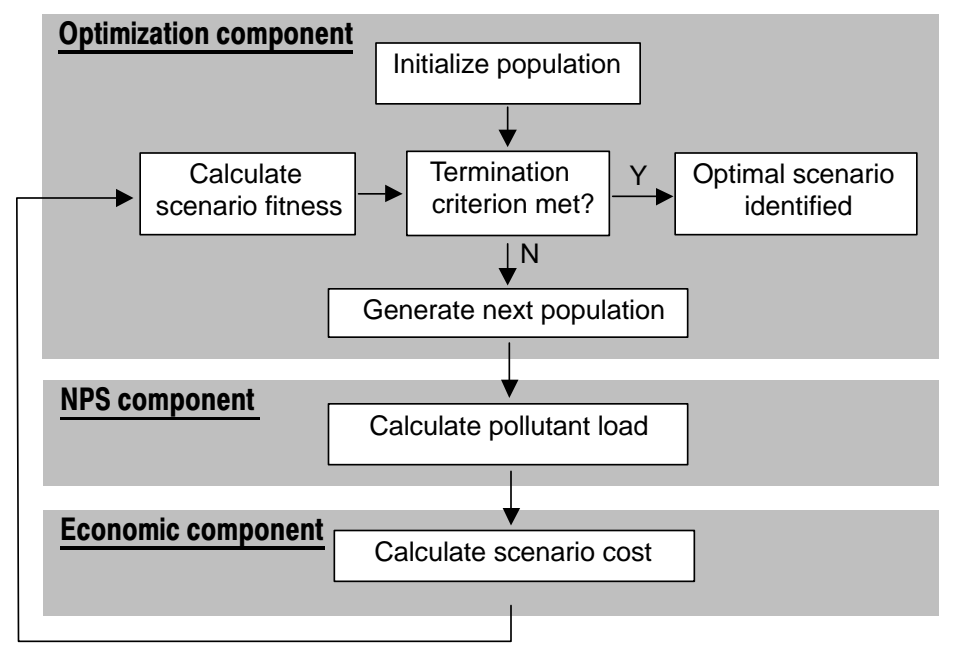

Figure 1. Basic steps of optimization procedure.

within the targeting combination. Cropland management and, in some cases, pasture and hay land varied across the evaluation runs, as indicated in table 1.

The optimization procedure developed by Veith et al. (2003) was used in this study. The optimization procedure is comprised of three components (optimization, NPS prediction, and economic analysis) within a GA framework (fig. 1). The optimization procedure was applied to the three optimization plans to determine BMP scenarios. The impact of the targeting strategy on sediment yield and cost was also determined using the NPS and economic components of the optimization procedure.

\section{Sediment Yield Prediction}

The NPS component estimates sediment yield based on gross erosion calculated with the Universal Soil Loss Equation (USLE) and a sediment routing routine developed by Veith (2002). The sediment routing component of the optimization procedure accounts for downstream effects on sediment delivery (Veith et al., 2003). The watershed is divided into cells using a geographic information system (GIS). A delivery ratio for each cell is calculated and applied both to gross erosion generated within a cell and to sediment flowing into a cell. Delivery from each cell is then routed along the flow path to obtain the net sediment yield of each cell to the watershed outlet.

Six factors must be quantified for the USLE: rainfall-runoff $(R)$, soil erodibility $(K)$, slope steepness $(S)$, slope length $(L)$, cropping-management $(C)$, and support practice $(P)$. An $R$ value of $2800 \mathrm{MJ} \cdot \mathrm{mm} /($ ha h yr) (Schwab et al., 1993) was used for the case study watershed. The USLE erodibility $K$ factor, taken from the SSURGO soil survey (USDANRCS, 2001) and converted to SI units, ranged from 0.0067 to $0.057 \mathrm{Mg}$ ha $\mathrm{h} /($ ha $\mathrm{MJ} \mathrm{mm})$ for soils in the watershed. The $S$ factor was calculated from slope, based on the digital elevation model (DEM). The $L$ factor was based on a flow length of $45 \mathrm{~m}$, which is a characteristic length of nonconcentrated flow for fields in this region (B. Cubbage, Natural Resource Technician, USDA-NRCS, Harrisonburg, Va., personal communication, 4 March 2002). The $C$ factors were obtained from USDA-NRCS (1988) and B. Cubbage (Natural Resource Technician, USDA-NRCS, Harrisonburg, Va., personal communication, 4 March 2002). A $P$ factor of one was used for all fields.

Separate sediment delivery equations are used in the optimization procedure for overland flow and for two types of channel flow: shallow concentrated flow, and ephemeral or perennial stream flow. Sediment delivery through overland flow cells is modeled as a function of land use cover, slope steepness, and flow length:

$$
d=\min \left\{\alpha \sqrt{\frac{s}{f}}, 1\right\}
$$

where

$d=$ sediment delivery ratio through an overland cell

$\alpha=$ land use coefficient (dimensionless)

$s=$ slope steepness across cell $(\mathrm{m} / \mathrm{m})$

$f=$ length of flow path across cell (m).

Development of equation 1 is described in detail by Veith et al. (2003). The slope steepness and length of flow path across each overland cell are determined by a GIS. Veith (2002) determined values of the empirical coefficient $(\alpha)$ based on calculations with the field-scale NPS model, RUSLE2 (available at: http://bioengr.ag.utk.edu/rusle2/. Accessed 4 March 2002).

Higher delivery is expected in channel versus overland flow due to increased flow depth, velocity, and transport capacity. Channel cells can be identified from a DEM in terms of the number of upstream cells accumulating to create a channel cell. In the Ridge and Valley physiographic region of Virginia, where the case watershed is located, shallow concentrated flow was identified as flow accumulated from at least 60 cells but less than 200 cells using a $30 \mathrm{~m}$ DEM, and channel flow was defined as flow accumulated from at least 200 cells (Veith, 2002). The entire cell containing a stream is assigned the relevant stream delivery value; overland sediment moving to the channel is not treated separately for cells containing streams. Delivery ratios of 0.98 and 0.9998 were assigned for shallow concentrated flow and stream flow cells, respectively. These ratios were selected to represent the low level of deposition expected in small headwater, rural watersheds (T. A. Dillaha, Department of Biological Systems Engineering, Virginia Tech, Blacksburg, Va., personal communication, 8 March 2002). For different sized watersheds, 
it may be desirable to adjust the cell sizes or to modify the channel definitions or delivery levels.

The sediment yield contribution of each cell is determined by routing sediment from the cell through downstream cells to the outlet. For each cell, the gross erosion is multiplied by the delivery ratios of cells in the flow path from the cell to the outlet:

$$
Y_{i}=A_{i} a_{i} \prod d_{j}
$$

where

$Y_{i}=$ sediment loss of cell $i$ reaching the outlet $(\mathrm{Mg})$

$A_{i}=$ gross erosion from cell $i(\mathrm{Mg} / \mathrm{ha})$

$a_{i}=$ area of cell $i$ (ha)

$d_{j}=$ sediment delivery ratio of cell $j$

$j$ indexes all flow path cells between cell $i$ and the outlet.

The ArcView GIS (Ver 3.2., Environmental Systems Research Institute, Redlands, Cal.) FlowLength function is used to closely approximate equation 2 by rewriting the product of the delivery ratios as an additive exponential function:

$$
\Pi d_{j}=e^{\sum \ln \left(d_{j}\right)} \approx e^{- \text {FlowLength }\left(t_{j} \times \frac{\operatorname{-n}\left(d_{j}\right)}{f_{j}}\right)}
$$

where

$d_{j}=$ sediment delivery ratio of cell $j$

$f_{j}=$ flow length assigned to cell $j$

$t_{j}=$ travel distance of flow between cell $j$ and the next cell in the flow path.

Summing the sediment loss reaching the outlet (i.e., the $Y_{i}$ values) over all cells and dividing by the watershed area gives the sediment yield of the watershed in $\mathrm{Mg} / \mathrm{ha}$.

\section{ECONOMic AnALYsis}

The economic component requires a variety of inputs, which were determined for the case watershed as follows. Average annual costs for each farmer were calculated from enterprise production costs, historical selling prices, and soil productivity. Production costs (\$/ha) were determined from the Virginia Farm Management Crop and Livestock Enterprise Budgets (VCE, 1999, 2001). Production costs included seed, fertilizer, machinery, and labor costs for the enterprise. Land ownership and tax costs were excluded, as were farm planning and management costs. These values do not change with respect to the management practice adopted. Selling prices were calculated from buying prices (VASS, 2001) by subtracting a combined cost for marketing and transportation (D. J. Bosch, Department of Agricultural and Applied Economics, Virginia Tech, Blacksburg, Va., personal communication, 7 March 2002). The pasture rent was taken from VCE (2001). Soil productivity values (quantity/ha) were determined from the NutLite computer program, which is an interface to NutMan (V2, ISIS Lab, Department of Entomology, Virginia Tech, Blacksburg, Va. Available at: www.isis.vt.edu/dss/nutman. Accessed 18 April 2002; Stone, 1995); the Virginia Nutrient Management Handbook (VADCR, 1993); and J. C. Baker (Department of Crop and Soil Environmental Sciences, Virginia Tech, Blacksburg, Va., personal communication, 14 March 2002).

Public costs were taken from Carpentier et al. (1998) and annualized over a period matching the five-year rotation length of hay set by the enterprise budgets. All other management practices were either single-year or five-year rotations.

\section{Optimization}

A GA is conceptually based on natural selection techniques seen in biological evolution (Goldberg, 1989; Chambers, 1995; Srivastava et al., 2002). Basic GAs model individuals of a population as chromosomes, with genes on each chromosome defining relevant traits of that individual. The possible values of each gene form a selection set for the gene. New individuals are created through crossover and random mutation. Chromosomes judged to be most fit are most likely to survive into the next generation.

In the optimization procedure by Veith et al. (2003), a watershed scenario is modeled as a chromosome. Each field in the watershed is represented as a gene and is associated with a selection set of possible management practices specific to that field. At each iteration in the optimization procedure, a number of scenarios are considered for addition into the GA population. Each scenario is evaluated by the NPS and economic components, which calculate watershedlevel pollutant load and cost, respectively. These values are converted into fitness scores, allowing scenarios to be compared and the best (most fit) scenarios selected. If two scenarios both meet the target pollutant load, then the scenario with the lower implementation cost is the better (more fit) scenario. The next population is created from the set of scenarios having the highest degree of fitness, and the process continues until a pre-established termination criterion is reached.

Population size and reproduction parameters, such as crossover rate, mutation rate, and replacement level, impact a GA's efficiency. Population size refers to the number of scenarios evaluated at each generation of the GA. At each generation, new scenarios are created from existing scenarios through crossover and/or mutation. Crossover refers to creation of a new scenario by combining information from two existing scenarios. For example, in this study, crossover of two scenarios creates a new scenario by combining BMP placements for some of the fields in the watershed from the first existing scenario with BMP placements for the remaining fields from the second existing scenario. The mutation rate is the probability that the value of any gene (management practice selected for a field) will be randomly changed while creating a new scenario. The replacement level controls the fraction of the population that is replaced through crossover or mutation at each generation.

Initial selection of the most efficient combination of parameter values for a given problem is often complex. Mitchell (1999) cautioned that ideal parameter values are likely to vary for different problem types and applications as a result of problem formulations and performance criteria. Use of large number optimization heuristics, such as the GA, in determining BMP placement cost-effectiveness has only been reported recently in the literature. In particular, there is a lack of previous research on the specific one-dimensional array problem formulation used by the optimization procedure. Hence, the first step in applying the optimization procedure was to determine efficient operating parameters for the GA within the context of this problem. Parameters were developed for the topography, soil, climate, and land use conditions typical of the case study location. While these parameters may also be effective for alternate locations with 
similar physiographic and climatic conditions, confirmation or re-evaluation of parameters may be necessary, particularly in different locations, for further applications of the optimization procedure.

Population size, crossover rate, and mutation rate typically interact nonlinearly (Mitchell, 1999). Thus, determining these parameters in different orders may affect the combination selected. Population size and replacement level impact the number of evaluations performed and, thus, computer runtime. As a result, these two parameters were determined first for this research. Crossover was determined next. Crossover is often considered the main method in a GA of introducing variation and exploring the search space (Mitchell, 1999). In contrast, mutation is viewed primarily as a method of preventing given genes within each individual from becoming permanently fixed. As such, crossover performs a more crucial role than mutation. The mutation rate, considered the least important parameter in the overall efficiency of the GA, was determined last.

A large population size enables more of the search space to be sampled with each generation. However, most watershed-level simulation models take several minutes or even several hours for a single evaluation. Because fewer evaluations per generation are made when using a smaller population size, a small population size is desirable in reducing computer runtime to a feasible length. A small population allows less of the response surface to be evaluated as compared with a larger population.

Similarly, high replacement levels were desired to maintain breadth in sampling across the search space. In a GA with a high replacement level, only the few most fit individuals are carried over from one population to the next. This ensures that the best-ever solutions will be maintained but allows most of the individuals in each population to continue sampling the search space through crossover and mutation. Like a large population size, a high replacement level increases the number of evaluations per generation and thus the computer runtime.

Thus, it was desirable to select a combination of population size and replacement level that would minimize computer runtime but still sample the response surface broadly enough to locate an optimal solution set. To this end, the impact of population size and replacement on the convergence of the GA was evaluated for ten combinations (table 2). Replacement levels were chosen to correspond with population sizes such that at least three individuals were carried over to the next generation.

Initial crossover and mutation rates of 0.9 and 0.05 , respectively, were used to determine the population size and replacement level. These rates were based on the literature (De Jong, 1975; Grefenstette, 1986; Schaffer et al., 1989; Liong et al., 1995; Mulligan and Brown, 1998). The initial mutation rate, slightly higher than suggested by the literature, was chosen to add increased diversity in the smaller populations. A 0.9 crossover rate means that every two individuals selected from the preceding generation have a 0.9 probability of being combined through crossover. A 0.05 mutation rate means that each gene in each individual has a 0.05 probability of being mutated.

Fitness scores for runs with larger populations showed the lowest rate of improvement with respect to number of evaluations (fig. 2). Over an equivalent number of evaluations, the lower population sizes of 10 and 15 increased in fitness at a higher rate than the remaining combinations. The
Table 2. Tested combinations of population size and replacement level.

\begin{tabular}{cccc}
\hline \multirow{2}{*}{$\begin{array}{c}\text { Population } \\
\text { Size }\end{array}$} & \multicolumn{3}{c}{ Replacement Level } \\
\cline { 2 - 4 } 100 & $90 \%$ & $70 \%$ & $50 \%$ \\
50 & $\mathrm{X}$ & $\mathrm{X}$ & \\
25 & & $\mathrm{X}$ & \\
15 & & $\mathrm{X}$ & $\mathrm{X}$ \\
10 & & $\mathrm{X}$ & $\mathrm{X}$ \\
& & $\mathrm{X}$ & $\mathrm{X}$ \\
\hline
\end{tabular}

population size of 15 with $70 \%$ replacement performed better than all other combinations after an initial period of about 2000 individuals evaluated. The larger population size of 15 with $70 \%$ replacement has an advantage over the population size of 10. Because more individuals in the population size of 15 are available in each generation for crossover and mutation, more of the search space will be sampled. Thus, the population size of 15 with $70 \%$ replacement was selected. Although this combination of initial conditions is not necessarily ideal for all watersheds, the arguments for a low population size and high replacement level still hold.

For the population size of 15 with $70 \%$ replacement, three crossover rates $(0.85,0.90$, and 0.95$)$ were compared (fig. 3 ). Based on the overall performance, a 0.90 crossover rate was selected for the remainder of the evaluations. For this combination, mutation rates were varied from 0.005 to 0.07 (fig. 4). As expected, the fitness score improved more quickly as decreasing mutation rates introduced less random fluctuation into each population. However, when the mutation rate was decreased to 0.005 , increase in fitness score fell below that of all other tested mutation rates, indicating that the randomness introduced in each generation was not sufficient to prevent scenarios from focusing on local optima. The 0.01 mutation rate, which showed the most consistent rate of increase and achieved the highest fitness score, was selected.

The focus of this research was to determine if the optimization procedure could identify a set of solutions more cost-effective than a given targeting strategy. Thus, optimization run-length depended more strongly on achieving an acceptable cost-effectiveness level within a reasonable run-length than on achieving a particular degree of convergence. A graph (fig. 5) of the highest scoring scenario of each generation versus pollution target load, pollution reduction from baseline, and watershed cost was used to determine how long a simulation should run before termination. This graph was easily updated and evaluated throughout the simulation using a spreadsheet program. Based on information provided by the graph, the simulation was continued until the pollutant targeting criterion was met and the incremental decrease in total watershed cost became negligible.

\section{Results AND Discussion}

Applying the targeting strategy to the baseline scenario reduced watershed sediment yield from $3,450 \mathrm{~kg} / \mathrm{ha}$ to $640 \mathrm{~kg} / \mathrm{ha}$, an $81 \%$ reduction. The maximum acceptable pollutant load for the optimization procedure was then set equal to the targeting strategy sediment yield $(640 \mathrm{~kg} / \mathrm{ha})$. Because optimization was designed to meet the maximum acceptable pollutant load, if possible, and then focus on cost reduction, and because this pollutant goal was always met, decrease in sediment yield from the baseline for all evaluations was the same: $2,810 \mathrm{~kg} / \mathrm{ha}$ (table 3 ). 


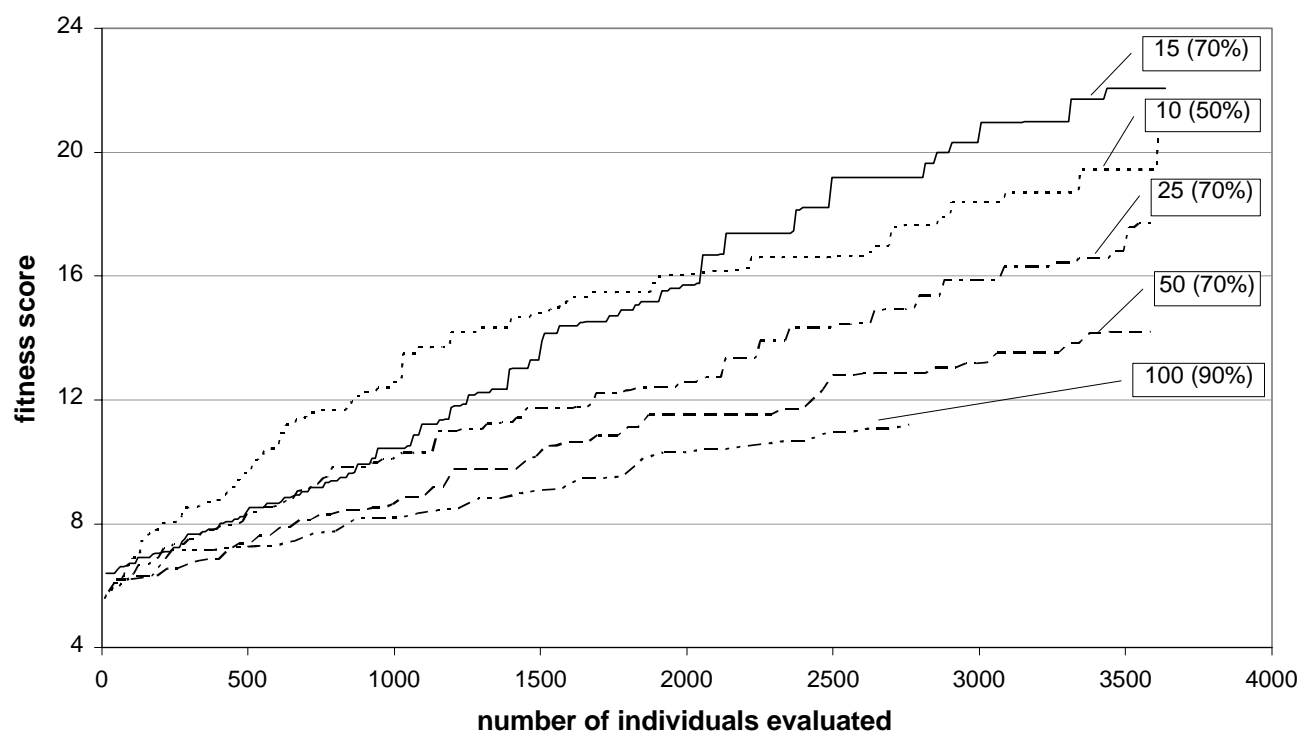

Figure 2. Convergence patterns over a similar runtime for varying initial conditions, listed by population size (replacement level in parentheses).

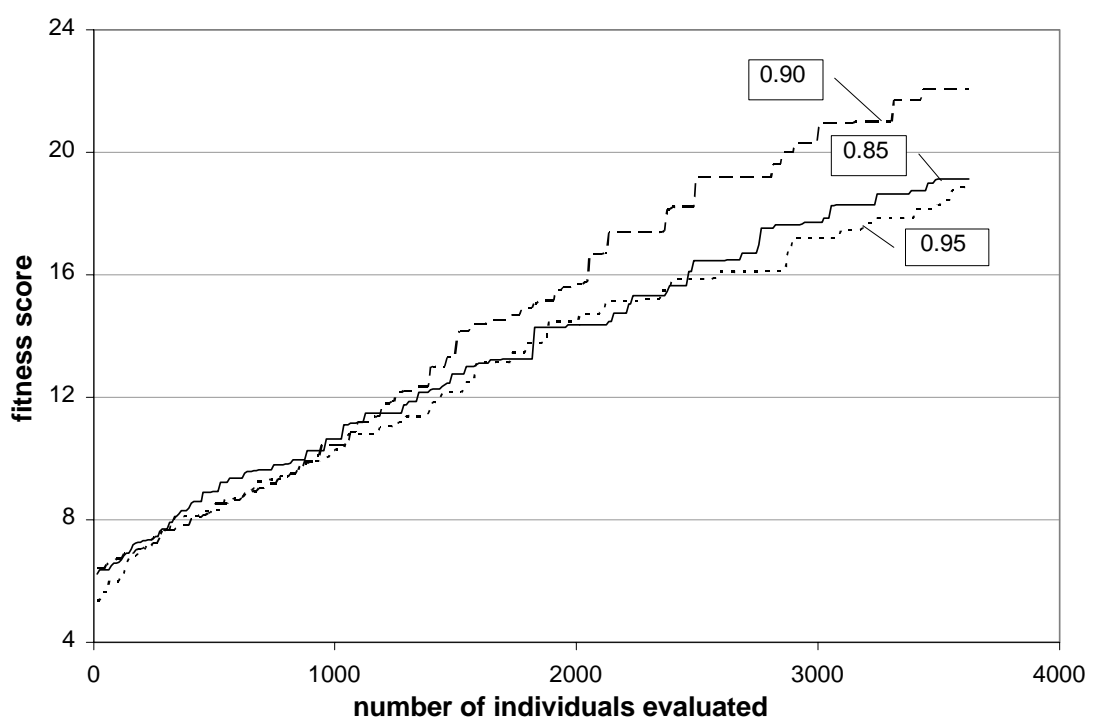

Figure 3. Crossover rate comparison for population size 15, $70 \%$ replacement, and 0.05 mutation rate.

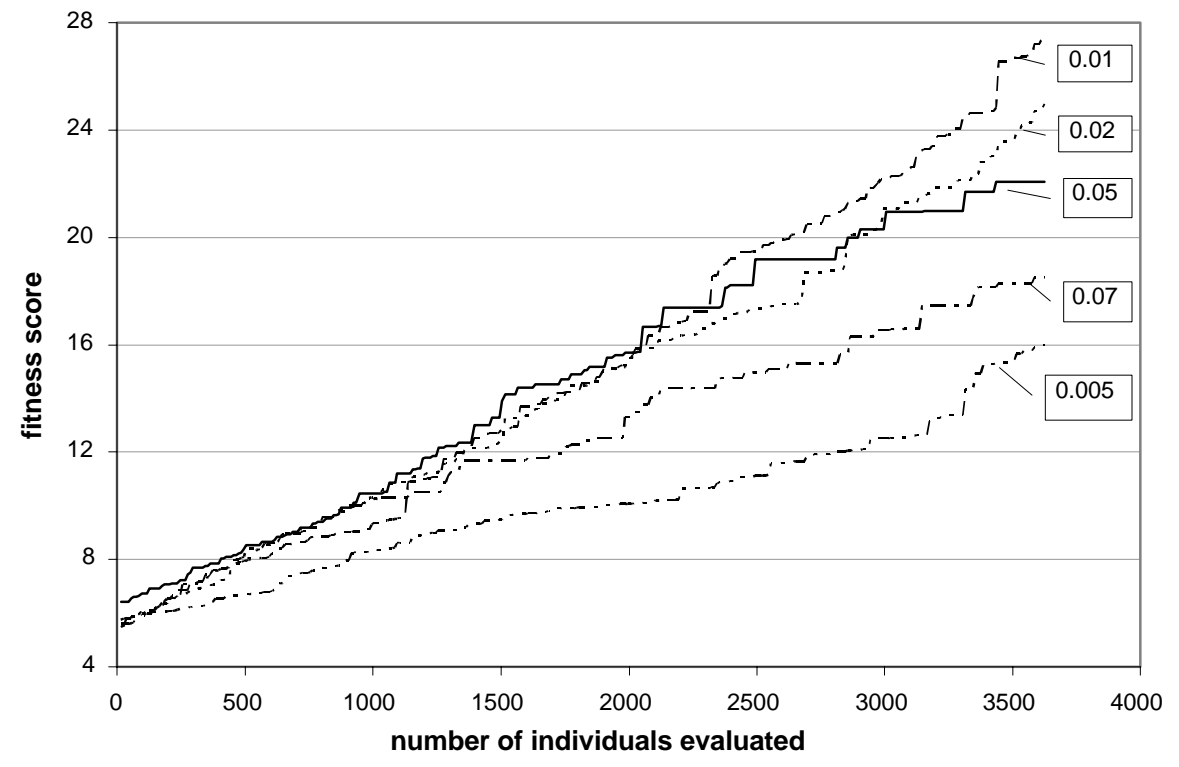

Figure 4. Mutation rate comparison for population size $15,70 \%$ replacement, and 0.90 crossover rate. 


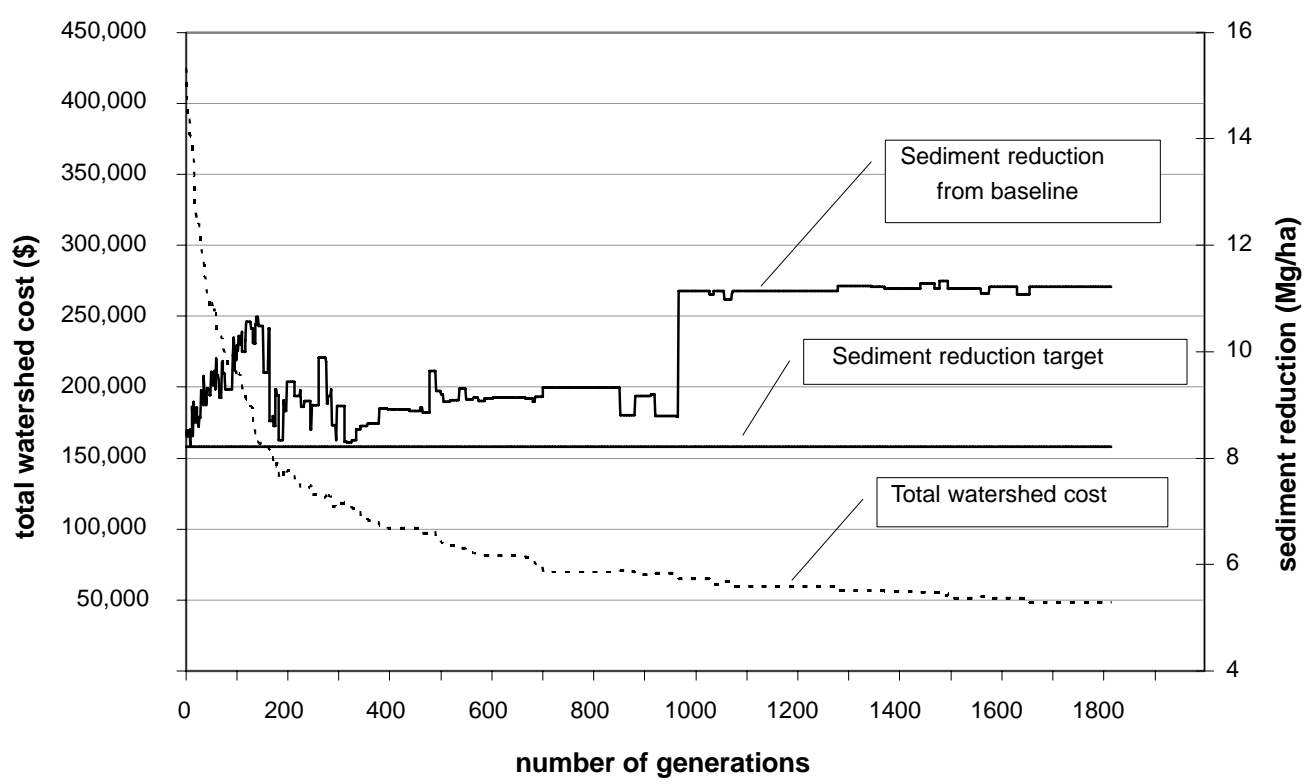

Figure 5. Best of generation watershed cost and pollutant reduction values for a single optimization run.

Table 3. Average annual sediment yield and watershed costs for the targeting strategy and three optimization solutions.

\begin{tabular}{lccc}
\hline & $\begin{array}{c}\text { Sediment } \\
\text { Decrease } \\
\text { from Baseline } \\
(\mathrm{kg} / \mathrm{ha})\end{array}$ & $\begin{array}{c}\text { Cost } \\
\text { Increase } \\
\text { from Baseline } \\
(\$)\end{array}$ & $\begin{array}{c}\text { Cost } \\
\text { Effectiveness } \\
\text { of Solution } \\
\$ /(\mathrm{kg} / \mathrm{ha})\end{array}$ \\
\hline Targeting & 2810 & 134,892 & 48.00 \\
Optimization plan 1 & 2810 & 117,426 & 41.79 \\
Optimization plan 2 & 2810 & 89,748 & 31.94 \\
Optimization plan 3 & 2810 & $-6,639$ & -2.36 \\
\hline
\end{tabular}

Cost increase for all evaluations (table 3) reflected the decrease in net return realized by the solution scenario as compared to the baseline scenario. Cropland, which was all in corn silage, was the only land use considered for BMPs under the targeting strategy and optimization plans 1 and 2 . As a result, the management practice of highest profit for each field (conventionally tilled corn silage) was identical across these three BMP placement strategies. For these three strategies, the baseline scenario was profit maximizing and any change in management practice from the baseline resulted in a decreased net return. Thus, the cost increase column in table 3 was always positive for these three strategies.

In optimization plan 3, hay and pasture were allowed to convert to cropland. The profit maximizing scenario for optimization plan 3 would have been to place all originally identified hay, pasture, and cropland into conventionally tilled corn silage. However, the baseline retained the originally identified hay and pasture. Thus, for optimization plan 3, the baseline was not profit maximizing and a change in management practice could potentially result in increased net return. This increase in net return is seen in the solution scenario (table 3) and is indicated by the negative value of cost increase from the baseline. In this plan, fields in hay or pasture were allowed to convert and did convert to corn silage whenever the conversion decreased costs and still met the pollutant targeting criterion.

Cost-effectiveness of each solution (table 3) was calculated as increase in total cost divided by sediment reduction. Cost-effectiveness in the optimization plans improved from that of the targeting strategy as more management practices were allowed. For example, under the targeting strategy, it was estimated to cost $\$ 48$ for each $\mathrm{kg} / \mathrm{ha}$ of sediment controlled annually. Optimization plan 1 allowed only the BMP combinations available to the targeting strategy but used different rules for placing those combinations. As compared to targeting, optimization plan 1 was estimated to cost about \$6 less per $\mathrm{kg} / \mathrm{ha} / \mathrm{yr}$ of sediment controlled. In optimization plan 2 , which allowed subsets of the targeting strategy BMP combinations, the cost was reduced to $\$ 32$ per $\mathrm{kg} / \mathrm{ha} / \mathrm{yr}$ of sediment reduction. Implementing the solution scenario identified by optimization plan 3 was estimated to cost about $\$ 2$ less than the baseline for every $\mathrm{kg} / \mathrm{ha} / \mathrm{yr}$ of watershed-level sediment loss prevented. The optimization procedure found more cost-effective BMP combinations than the targeting strategy for all evaluation runs.

\section{Spatial Allocation}

Allocation of non-fixed management units, as defined in table 1, varied across the evaluation run solutions (table 4). Of the 68 fields placed in conventionally tilled corn silage in the baseline scenario (fig. 6a), only 10 remained in that practice in the targeting strategy (fig. 6b). The other 58 were assigned a BMP set of contour, minimum-tillage corn silage with a winter wheat cover crop.

Optimization plan 1 achieved the same level of pollution reduction as the targeting strategy, but with approximately one-third fewer fields put in minimum-tillage corn silage on the contour with a winter wheat cover crop (table 4). As compared to the targeting strategy (fig. 6b), plan 1 (fig. 6c) placed fewer BMPs on fields away from the streams. For example, all fields that predominantly had a slope greater than $3 \%$ were assigned the minimum-tillage BMP by the targeting strategy, while in optimization plan 1, primarily only those high-slope fields that bordered the stream had BMPs applied. The optimization solutions thus demonstrate the expected and desired outcome of identifying those fields near the stream as having a greater impact on sediment delivery from the watershed. This effect of spatial position in the watershed is conceptually reasonable and desirable, and 
Table 4. Agricultural BMP allocation for the baseline scenario, targeting strategy, and four optimization solutions (values are number of fields, with area in hectares in parentheses).

\begin{tabular}{|c|c|c|c|c|c|c|c|c|c|c|c|c|}
\hline \multirow{2}{*}{$\frac{\text { Management Practice }{ }^{[\mathrm{a}]}}{\mathrm{CC}}$} & \multicolumn{2}{|c|}{ Baseline } & \multicolumn{2}{|c|}{ Targeted } & \multicolumn{2}{|c|}{ Plan 1} & \multicolumn{2}{|c|}{ Plan 2} & \multicolumn{2}{|c|}{$\begin{array}{c}\text { Plan 3, } \\
\text { Solution } 1\end{array}$} & \multicolumn{2}{|c|}{$\begin{array}{c}\text { Plan } 3, \\
\text { Solution } 2\end{array}$} \\
\hline & 68 & $(392.0)$ & 10 & $(34.7)$ & 28 & $(83.2)$ & 19 & $(42.5)$ & 24 & $(78.6)$ & 25 & $(85.6)$ \\
\hline $\mathrm{CC} / \mathrm{WW}$ & -- & & -- & & -- & & -- & & 2 & $(0.8)$ & 2 & $(0.4)$ \\
\hline $\mathrm{MC}$ & -- & & -- & & -- & & 4 & $(18.6)$ & 5 & $(15.3)$ & 4 & $(4.0)$ \\
\hline $\mathrm{MC} / \mathrm{WW}$ & -- & & -- & & -- & & 1 & $(6.6)$ & -- & & -- & \\
\hline $\mathrm{CC}(2 \mathrm{yr}) / \mathrm{H}(3 \mathrm{yr})$ & -- & & -- & & -- & & - & & 7 & $(42.2)$ & 6 & $(32.5)$ \\
\hline $\mathrm{CC}(1 \mathrm{yr}) / \mathrm{MC}(1 \mathrm{yr}) / \mathrm{H}(3 \mathrm{yr})$ & - & & -- & & -- & & -- & & 5 & $(37.2)$ & 3 & $(5.1)$ \\
\hline $\mathrm{H}$ & 44 & $(288.2)$ & 44 & $(288.2)$ & 44 & $(288.2)$ & 44 & $(288.2)$ & 3 & $(51.9)$ & 3 & $(51.9)$ \\
\hline Pasture & 13 & $(94.6)$ & 13 & $(94.6)$ & 13 & $(94.6)$ & 13 & $(94.6)$ & 15 & $(147.4)$ & 18 & $(184.0)$ \\
\hline $\mathrm{CC}$, contoured & -- & & -- & & -- & & 2 & $(3.3)$ & 28 & $(145.2)$ & 27 & $(141.8)$ \\
\hline MC, contoured & -- & & -- & & -- & & 23 & $(140.3)$ & 17 & $(103.6)$ & 19 & $(114.5)$ \\
\hline MC / WW, all contoured & -- & & 58 & $(357.4)$ & 40 & (308.9) & 19 & $(180.8)$ & -- & & -- & \\
\hline $\mathrm{CC}(2 \mathrm{yr}) / \mathrm{H}(3 \mathrm{yr})$, all contoured & -- & & -- & & -- & & -- & & 10 & $(112.9)$ & 8 & $(95.4)$ \\
\hline $\mathrm{CC}(1 \mathrm{yr}) / \mathrm{MC}(1 \mathrm{yr}) / \mathrm{H}$ (3 yr), all contoured & -- & & -- & & -- & & -- & & 9 & $(39.6)$ & 10 & $(59.6)$ \\
\hline
\end{tabular}

[a] $\mathrm{CC}=$ conventional corn silage; $\mathrm{WW}=$ winter wheat $\mathrm{MC}=$ minimum till corn silage; $\mathrm{H}=$ grass hay.
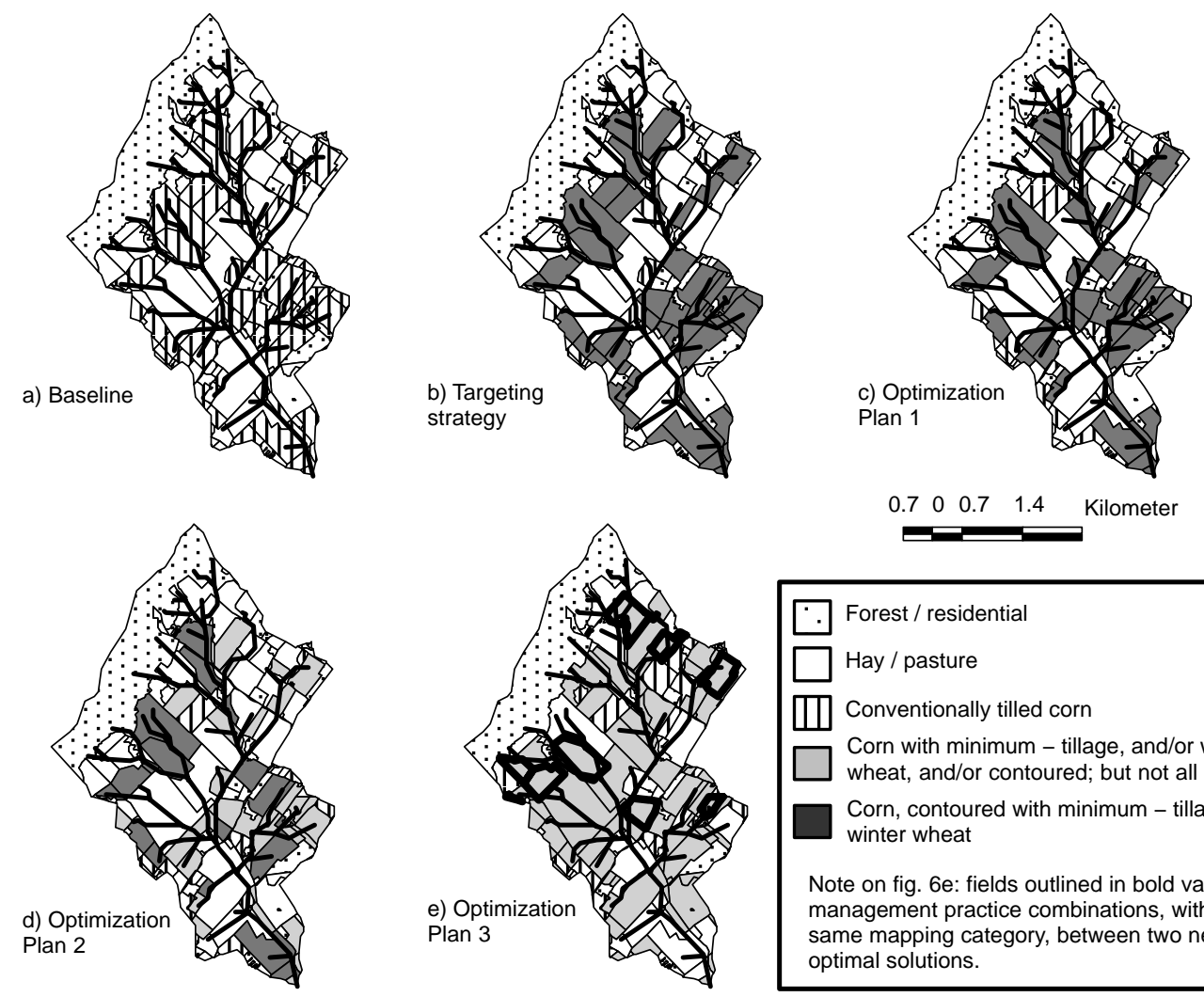

$\begin{array}{lllll}0.7 & 0 & 0.7 & 1.4 & \text { Kilometer }\end{array}$
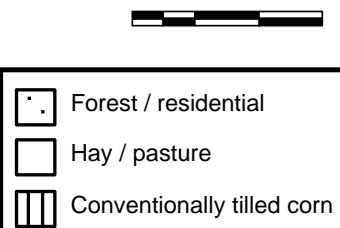

$\prod$ Conventionally tilled corn

Corn with minimum - tillage, and/or winter wheat, and/or contoured; but not all three

Corn, contoured with minimum - tillage and winter wheat

Note on fig. 6e: fields outlined in bold varied in management practice combinations, within the same mapping category, between two near optimal solutions.

Figure 6. Agricultural land use allocation for the baseline scenario and compared evaluation runs.

in this model, is a direct reflection of the relationships built into the sediment transport component.

Plan 2 primarily placed fields along the watershed edge in conventionally tilled corn silage and fields along the streams in contoured, minimum-tillage. As with the targeting strategy and plan 1, plan 2 (fig. 6d) placed fields with steeper slopes along the stream in the full BMP combination of contour, minimumtillage corn silage with a winter wheat cover crop. However, plan 2 implemented the full BMP combination on 21 fewer fields than did plan 1 and 39 fewer than did the targeting strategy (table 4). Additionally, plan 2, which could select to implement only part of the BMP combination available to the targeting strategy and plan 1, implemented at least one BMP on nine more fields than did plan 1 .
As expected, solutions from optimization plan 3 (fig. 6e) included a more diverse set of management practices. All available management practices except minimum-tillage corn silage with a winter wheat cover crop, with and without contour tillage, were selected (table 4). About $22 \%$ of the agricultural land was allocated to conventionally tilled corn silage, with or without contouring. The diversity of practices selected by the optimization indicates that variation could be introduced into the watershed while still meeting the target pollutant load.

Two scenarios in the optimal solution set of plan 3 were compared to gain a better understanding of the impacts of different BMPs on the watershed. Only a few fields, indicated by a bold outline in figure $6 \mathrm{e}$, varied in management practice 
Table 5. Cost-benefit analysis of targeting and optimization.

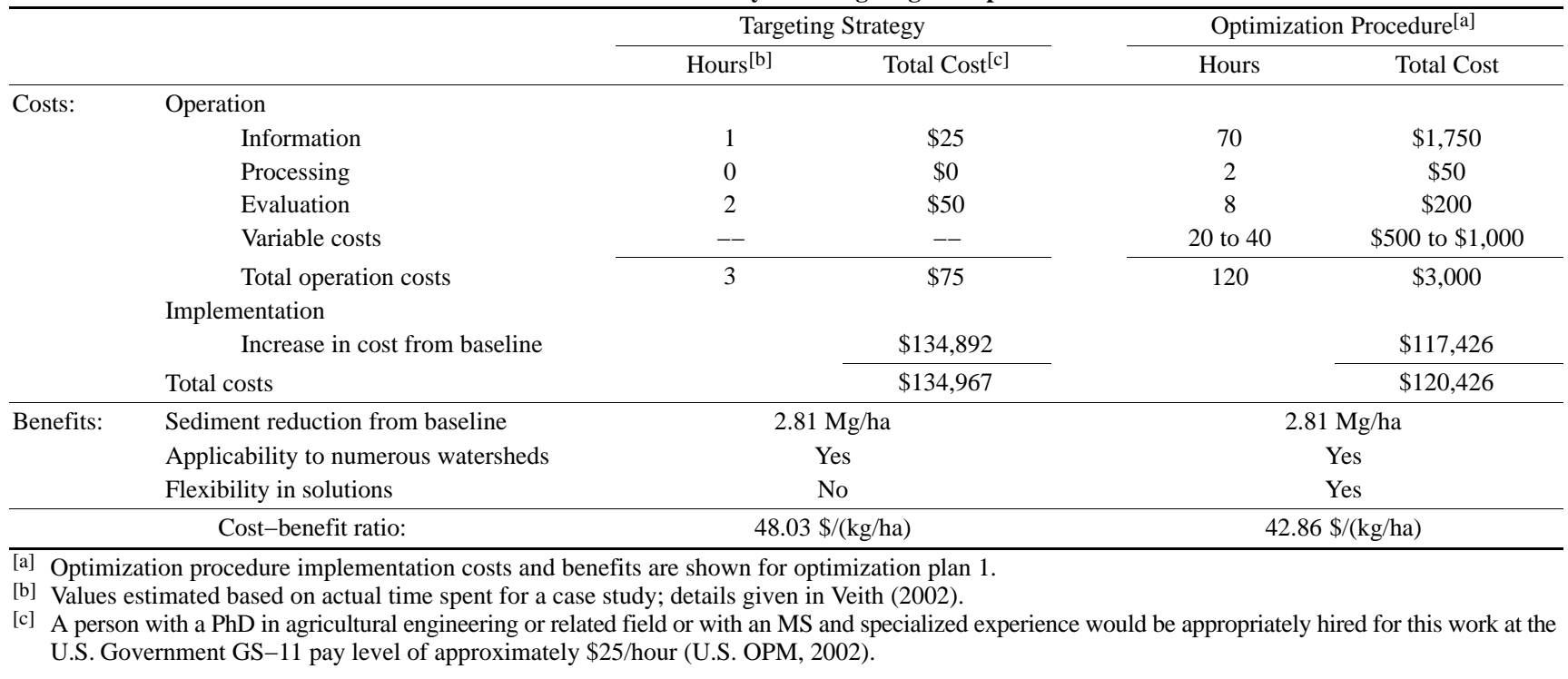

between two near-optimal plan 3 solution scenarios. The fact that these fields can vary without substantially impacting the cost-effectiveness of the total solution scenario indicates that overall cost-effectiveness of the scenario is less sensitive to choices of management practice for these fields than those of other fields. By providing this type of sensitivity analysis, an optimization procedure enables flexibility in implementing a cost-effective solution. For example, farmers managing the less sensitive fields can consider a choice of management practices for those fields without substantially decreasing overall cost-effectiveness on the watershed. The greater the number of fields available for a choice of practices, the more the preferences of the farmers and other stakeholders can be considered, which ultimately improves the likelihood of watershed-wide implementation of the critical management practices.

\section{Cost-Benefit Analysis}

An overall cost-benefit analysis of optimization in comparison to targeting was performed to determine the operational feasibility of using optimization. Public costs associated with operation of the targeting and optimization methods were considered, as well as costs and benefits resulting from solution implementation. Public operation costs included information costs, processing costs, and evaluation costs. One-time costs (approximately \$5,000) involved in purchasing and configuring a computer with GIS and analysis software were not considered.

Table 5 summarizes cost-benefit analysis results for the targeting and optimization plan 1 procedures. Implementation costs of the other optimization plans in this case study would vary, as shown in the "cost increase from baseline" column of table 3 , but operation costs would remain constant. For optimization plan 1, substantial savings in BMP implementation resulted in a $\$ 5$ savings per $\mathrm{kg} / \mathrm{ha}$ of sediment reduced as compared with targeting, even when both operational and implementation costs were considered (table 5). Plans 2 and 3 saved $\$ 15$ and $\$ 49$ per $\mathrm{kg} / \mathrm{ha}$ reduction, respectively, over targeting.

The favorable cost-benefit ratios of all optimization plans were due to meeting the same reduction in pollutant loading as the targeting strategy while reducing average annual costs. An additional benefit of the optimization procedure was the potential flexibility in solutions to suit stakeholders while still meeting the pollutant load criterion.

\section{SuMmary AND CONCluSIONS}

Optimization and targeting were compared to determine if selection of BMPs through optimization can meet NPS reduction goals at a lower cost than a targeting approach. A baseline scenario, a targeting strategy, and three optimization plans were compared for a case study watershed in Virginia. The baseline scenario represented a watershed without NPS control measures. The targeting strategy applied a comprehensive set of BMPs to cropland based on a watershed-independent set of rules. The optimization allowed various subsets of the same set of BMPs and applied them based on fitness rules defined in a GA-based optimization procedure.

An efficient combination of GA parameters was determined for the specific problem formulation used by the optimization procedure. The cost-effectiveness of the optimization procedure and targeting strategy were compared, and a cost-benefit analysis was performed. Additionally, differences in BMP allocation were compared across solution scenarios from the two techniques.

As compared to targeting, the optimization procedure:

- met the same pollution reduction criterion,

- generated BMP scenarios with lower costs,

- found solutions of higher cost-effectiveness and higher cost-benefit ratios, and

- provided a choice of management practices for noncritical fields, through identification of alternative near-optimal solutions.

Targeting is plan-based and can be universally applied with limited watershed-specific knowledge or data collection. Application of a performance-based optimization procedure is more data intensive. Previous modeling of a watershed can decrease setup time by providing necessary data, baseline and management scenarios, and knowledge of the watershed and of its stakeholders, all of which are useful to the optimization procedure. Thus, as more watersheds are 
modeled, additional requirements of optimization over targeting diminish.

The optimization plans had better cost-benefit ratios, providing equivalent reduction in pollutant loading as the targeting strategy while reducing average annual costs. Additionally, the optimization procedure offers flexibility in implementation by providing a number of near-optimal solutions, which offers alternatives to stakeholders while still meeting the pollutant load criterion. The advantages, then, of optimization over targeting may prove quite beneficial in continuing efforts to control NPS pollution in a cost-effective manner.

\section{REFERENCES}

Carpentier, C. L., D. J. Bosch, and S. S. Batie. 1998. Using spatial information to reduce costs of controlling agricultural nonpoint-source pollution. Agric. and Resource Economics Review 27(1): 72-84.

Chambers, L., ed. 1995. Practical Handbook of Genetic Algorithms: Applications, Volume 1. Boca Raton, Fla.: CRC Press.

De Jong, K. A. 1975. An analysis of the behavior of a class of genetic adaptive systems. PhD diss. Ann Arbor, Mich.: University of Michigan. Cited in Mitchell (1999).

Dickinson, W. T., R. P. Rudra, and G. J. Wall. 1990. Targeting remedial measures to control nonpoint-source pollution. Water Resources Bulletin 26(3): 499-507.

Goldberg, D. E. 1989. Genetic Algorithms in Searching, Optimization, and Machine Learning. Reading, Mass.: Addison Wesley.

Grefenstette, J. J. 1986. Optimization of control parameters for genetic algorithms. IEEE Trans. on Systems, Man, and Cybernetics 16(1): 122-128. Cited in Mitchell (1999).

Heatwole, C. D., A. B. Bottcher, and L. B. Baldwin. 1987. Modeling cost-effectiveness of agricultural nonpoint pollution abatement programs on two Florida basins. Water Resources Bulletin 23(1): 127-131.

Liong, S., W. T. Chan, and J. ShreeRam. 1995. Peak-flow forecasting with genetic algorithm and SWMM. J. Hydraulic Eng. 121(8): 613-617.

Mitchell, M. 1999. An Introduction to Genetic Algorithms. Cambridge, Mass.: The MIT Press.

Mulligan, A. E., and L. C. Brown. 1998. Algorithms for calibrating water quality models. J. Environmental Eng. 124(3): 202-211.

Schaffer, J. D., R. A. Caruana, L. J. Eshelman, and R. Das. 1989. A study of control parameters affecting online performance of genetic algorithms for function optimization. In Proc. Third International Conference on Genetic Algorithms, 51-60. J. D. Schaffer, ed. San Mateo, Cal.: Morgan Kaufmann.
Schwab, G. O., D. D. Fangmeier, W. J. Elliot, and R. K. Frevert. 1993. Soil and Water Conservation Engineering. New York, N.Y.: John Wiley and Sons.

Srivastava, P., J. M. Hamlett, P. D. Robillard, and R. L. Day. 2002. Watershed optimization of best management practices using AnnAGNPS and a genetic algorithm. Water Resources Research 38(3): 1-14.

Stone, N. D. 1995. Whole-farm planning for crop/livestock farms: Integrating nutrient management. In FACTS 95 Conference Proc., 255-261. Ithaca, N.Y.: Cornell University.

USDA-NRCS. 1988. Crop management factors - mountains and valleys - area II. NRCS Field Office Technical Guide 120-411. Washington, D.C.: USDA Natural Resources Conservation Service.

USDA-NRCS. 2001. SSURGO documentation. Washington, D.C.: USDA Natural Resources Conservation Service. Available at: http://gis.itc.nrcs.usda.gov/docs/SSURGO_Documentation.html. Accessed 15 January 2001.

U.S. OPM. 2002. USDA salary table 2002-RUS. Washington, D.C.: U.S. Office of Personnel Management. Available at: http://www.opm.gov/oca/02tables/RUS_h.htm. Accessed 19 April 2002.

VA-DCR. 1993. Nutrient Management Handbook. Richmond, Va.: Virginia Department of Conservation and Recreation.

VASS. 2001. Virginia Agricultural Statistics Bulletin and Resource Directory, Number 75. Richmond, Va.: Virginia Agricultural Statistics Service.

VCE. 1999. Virginia Farm Management Crop and Livestock Enterprise Budgets. Publication 446-047. Blacksburg, Va.: Virginia Tech, Virginia Cooperative Extension.

VCE. 2001. Land rental guide for the Shenandoah Valley. Blacksburg, Va.: Virginia Tech, Virginia Cooperative Extension. Available at: www.ext.vt.edu/news/periodicals/fmu/2001-02/landrental.html. Accessed 14 August 2003.

Veith, T. L. 2002. Agricultural BMP placement for cost-effective pollution control at the watershed level. PhD diss. Blacksburg, Va.: Virginia Tech. Available at: http://scholar.lib.vt.edu/theses/available/etd-04252002-132437/.

Veith, T. L., M. L. Wolfe, and C. D. Heatwole. 2003. Optimization procedure for cost-effective BMP placement at a watershed scale. J. American Water Resources Assoc. 39(6): 1331-1343.

Willis, L. M., S. B. Forrest, J. A. Nissen, J. G. Hiscock, and P. V. Kirby. 1994. Analysis of on-farm best management practices in the Everglades agricultural area. In Environmentally Sound Agriculture: Proc. Second Conference, 93-99. St. Joseph, Mich.: ASAE. 